\title{
Measuring the Degrees of Openness of Educational Journals in China with the Open Access Spectrum (OAS) Evaluation Tool
}

\author{
Dongdong Lv \\ Office of Academic Research, Zhejiang Open University, Hangzhou, China \\ Email: ddrf1991@163.com
}

How to cite this paper: Lv, D.D. (2021) Measuring the Degrees of Openness of Educational Journals in China with the Open Access Spectrum (OAS) Evaluation Tool. Open Access Library Journal, 8: e8245. https://doi.org/10.4236/oalib.1108245

Received: November 30, 2021

Accepted: December 12, 2021

Published: December 15, 2021

Copyright $\odot 2021$ by author(s) and Open Access Library Inc.

This work is licensed under the Creative Commons Attribution International License (CC BY 4.0).

http://creativecommons.org/licenses/by/4.0/

\section{(c) (i) Open Access}

\begin{abstract}
At present, the information dissemination and acquisition behavior of scholarly journals have undergone great changes. Electronic resources have become an important information source, and the subjects of network information release have become increasingly large, and instant access to information has become the mainstream trend. In order to promote the dissemination and exchange of academic information in the era of big data, and promote free and convenient access to scientific research results, more and more journals in China have joined the ranks of "open access". This paper aims to reveal the openness of educational journals in China, so that readers, researchers, research institutions and publishers can better understand the status quo of open access of Chinese journals. This study will adopt the OAS tool proposed by SPARC, select 284 educational journals collected by CNKI as the research samples, and combine the actual situation in China, make appropriate improvements to the open evaluation tool, and use the improved evaluation tool and evaluation system to evaluate the openness of Chinese educational journals.
\end{abstract}

\section{Subject Areas}

Journalism and Communication, Library, Intelligence and Philology

\section{Keywords}

Open Access, Degrees of Openness, Open Access Spectrum Evaluation Tool

\section{Introduction}

As an important carrier of academic information, scholarly journals are impor- 
tant tools for spreading academic ideas, promoting academic exchanges, flourishing scientific undertakings and promoting social development. However, in recent years, the subscription price of scholarly journals has been rising, and some publishers even charge both "authors and readers" and "research institutions and academia", which has greatly increased the cost of obtaining academic results.

With the rapid development of new information technologies such as mobile Internet and cloud computing and the popularization of intelligent mobile terminals and social media, modern society has entered the era of big data, which involves mass production, storage, sharing and application of data. In this era, the information dissemination and acquisition behavior of scholarly journals have also undergone great changes. Electronic resources have become an important information source, the subject of network information release has become increasingly large, and instant access to information has become the mainstream trend. However, a large amount of academic information is still mainly obtained through a small number of comprehensive or professional platforms. Oligopoly resource acquisition platforms create an unfair competitive environment, which puts scholarly journals, research institutions, researchers, authors and readers in a vulnerable position.

In order to promote the dissemination and exchange of academic information in the era of big data and promote free, convenient access to scientific research results, more and more journals in China have joined the ranks of "Open Access" (OA). How open are Chinese scholarly journals at present?

On the basis of literature review, this paper draws on the Open Access Spectrum (OAS) Evaluation Tool and makes appropriate improvements in combination with China's national conditions to investigate and analyze the openness of CNKI online educational journals. This paper aims to reveal the degrees of openness of educational journals in China, so that readers, scholars, research institutions and publishers can better understand the status quo of open access of Chinese journals.

\section{Literature Review}

The idea of Open Access was first proposed in the Budapest Open Access Initiative (BOAI) in 2002. The definition of "open Access" from the BOAI is that: "By 'open access' to this literature, we mean its free availability on the public internet, permitting any users to read, download, copy, distribute, print, search, or link to the full texts of these articles, crawl them for indexing, pass them as data to software, or use them for any other lawful purpose, without financial, legal, or technical barriers other than those inseparable from gaining access to the internet itself. The only constraint on reproduction and distribution, and the only role for copyright in this domain, should be to give authors control over the integrity of their work and the right to be properly acknowledged and cited."1

${ }^{1}$ https://www.budapestopenaccessinitiative.org/faq/\#openaccess 
The initiative was signed by the Budapest participants and thousands of individuals and organizations from around the world who represent researchers, universities, laboratories, libraries, foundations, journals, publishers, learned societies, and kindred open access initiatives.

Since then, the open access movement has been developing rapidly, and has been recognized and supported by more and more researchers. They have carried out a series of relevant researches from different perspectives and levels, which can be summarized as the following four types of researches:

1) The study of the open access movement. In recent years, whether the number of open access journals is increasing, or the formulation and promotion of relevant policies, the open access movement abroad is growing exponentially. Many researchers have sorted out the declaration, origin, concept and connotation of open access. For example, Peter Suber (2012) [1] tells us what open access is and isn't, how it benefits authors and readers of research, how we pay for it, how it avoids copyright problems, how it has moved from the periphery to the mainstream, and what its future may hold. In addition, some scholars introduced the development status of open access movement in Pakistan, Africa, Asia and other countries or regions.

2) The research of stakeholders' understanding on open access, including authors, readers and publishers, among which the authors' attitude towards open access is the main research. For example, Teplitzky Samantha et al. (2016) [2] conducted a qualitative study of 138 individuals who had received the Berkeley Research Impact Initiative funding to survey their opinions about the benefits and funding of open access. The survey analyzed their views on the benefits and funding of open access and found that most respondents supported open access policies and believed that their articles would have more impact if they were published in open access, and expected multiple channels to fund open access costs. Nariani Rajiv et al. (2012) [3] gauge the uptake of library support for author funding and author satisfaction with open access publishing. Beard Regina M. (2016) [4] surveyed and analyzed graduates' perceptions of open access and found that they often used search engines such as Google Scholar for cross-library searches, thus being exposed to a large number of articles from open access journals.

3) The research on open access publishing. The European Union of Universities (EUA), which monitors the development of open access from an institutional perspective, reviewed the business model and cost, peer review and quality assessment of open access journal publishing in Europe. Neuman Yrsa et al. (2017) [5] used a philosophy journal as an example to analyze how it evaluated various publishing models and made an informed decision on how best to adopt open access publishing for the journal. Based on the analysis, they summarized the relevant elements of journal publishing and some methods to judge the feasibility of open access publishing.

4) The research on the academic influence of open access articles. For example, Zawacki-Richter et al. (2010) [6] examined 12 distance education journals (6 
open and 6 published in closed format by commercial publishers), computed differences between open and closed journals. McCabe Mark J. et al. (2013) [7] constructed a new model using economic theory to measure and compare the advantages and disadvantages of open access journals and traditional journals. Vaughan L. et al. used WoS database, Google Scholar and Google search engine as data statistical sources to evaluate the academic quality of social science open access journals by using web link indicators. To examine changes in the open access landscape over time, Arendt Julie et al. (2019) [8] conducted data analysis on articles from four disciplines. All of these studies show that open access articles are cited earlier and tend to be cited more often than traditional paid articles.

In general, the researches focus of scholars have gradually shifted from the connotation, characteristics, models and other theoretical frameworks of open access to specific empirical researches, and more discussions on the advantages and practical effects of open access.

\section{Methodology}

\subsection{Selected Journals}

In this study, 284 educational journals collected by China National Knowledge Infrastructure $(\mathrm{CNKI})$, the largest literature retrieval platform in China, were selected as research samples, including core journals included by CSSCI and Peking University, as well as general journals and journals with poor performance. So the research samples had good representativeness. We took the Annual Report of Impact Factors of Chinese Academic Journals (Humanities and Social Sciences) (2020 edition) published by CNKI as the reference and made statistics on the distribution of academic level of sample journals according to the size of impact factors. The specific results are shown in Table 1.

\subsection{The Open Access Spectrum Evaluation Tool}

In order to quantitatively evaluate open access journals, the Scholarly Publishing and Academic Resources Coalition (SPARC), the Public Library of Science (PLOS) and the Open Access Scholarly Publishers Association (OASPA), collaborated in 2013 to publish the manual How Open Is It? Based on this manual, the SPARC research team carried out a 16-month survey, combined with a large

Table 1. Distribution of impact factors of sample journals.

\begin{tabular}{ccc}
\hline Impact factor & Number of journals & Percentage of total \\
\hline Greater than 3.000 & 3 & $1.05 \%$ \\
$2.000-3.000$ & 9 & $3.17 \%$ \\
$1.000-1.999$ & 31 & $10.92 \%$ \\
$0.100-0.999$ & 141 & $49.65 \%$ \\
Less than 0.1 & 100 & $35.21 \%$ \\
\hline
\end{tabular}


number of expert opinions, and finally determined the OAS quantitative evaluation tool with a total score of 100 points, and clarified the scoring criteria of reading rights, reuse rights, copyrights, author posting rights, automatic posting, and machine readability.

The specific evaluation indexes and scoring criteria are as follows:

1) Reader rights: Free readership rights to all articles immediately upon publication (20 points); Free readership rights to all articles after an embargo of no more than 6 months (16 points); Free readership rights to all articles after an embargo greater than 6 months (12 points); Free and immediate readership rights to some, but not all, articles (including "hybrid" models) (5 points); Subscription, membership, pay-perview, or other fees required to read all articles $(0$ points).

2) Reuse rights: Generous reuse and remixing rights (e.g., CC BY license) (20 points). Reuse, remixing, and further building upon the work subject to certain restrictions and conditions (e.g., CC BY-NC and CC BY-SA licenses) (14 points); Reuse (no remixing or further building upon the work) subject to certain restrictions and conditions (e.g., CC BY-ND license) (7 points); Some reuse rights beyond fair use for some, but not all, articles (including "hybrid models") (4 points); No reuse rights beyond fair use/dealing or other limitations or exceptions to copyright (All Rights Reserved) (0 points).

3) Copyrights: Author holds copyright with no restrictions (16 points); Author retains/publisher grants broad rights, including author reuse (e.g., of figures in presentations/teaching, creation of derivatives) and authorization rights (for others to use) (10 points); Author retains/publisher grants limited rights for author reuse (e.g., of figures in presentations/teaching, creation of derivatives) (4 points); Publisher holds copyright, with no author reuse beyond fair use (0 points).

4) Author posting rights: Author may post any version to any repository or website with no delay (16 points); Author may post some version (determined by publisher) to any repository or website with no delay (10 points); Author may post some version (determined by publisher) to any repository or website with some delay (determined by the publisher) (6 points); Author may post some version (determined by publisher) to certain repositories or websites, with or without delays (4 points); Author may not deposit any versions to any repositories or websites at any time ( 0 points).

5) Automatic posting: Journals make copies of all articles automatically available in trusted third party repositories (e.g., PubMed Central, OpenAire, institutional) immediately upon publication (12 points); Journals make copies of all articles automatically available in trusted third-party repositories (e.g., PubMed Central, OpenAire, institutional) within 6 months (8 points); Journals make copies of all articles automatically available in trusted third-party repositories (e.g., PubMed Central, OpenAire, institutional) within 12 months (4 points); Journals make copies of some, but not all, articles automatically available in trusted third-party repositories (e.g., PubMed Central, OpenAire, institutional) 
within 12 months ( 2 points); No automatic posting in third-party repositories (0 points).

6) Machine readability: Article full text, metadata, supporting data (including format and semantic markup) and citations may be accessed viaAPI, with instructions publicly posted (16 points); Article full text, metadata, and citations may be accessed via API, with instructions publicly posted (12 points); Article full text, metadata, and citations may be crawled without special permission or registration, with instructions publicly posted (8 points); Article full text, metadata, and citations may be crawled with permission, with instructions publicly posted (4 points); No full text articles available for crawling ( 0 points).

\subsection{Construct the Evaluation Framework of Openness for Scholarly Journals in China Based on OAS Tool}

OAS tool adopts the way of spectrum, sets the score value of different grades, and clearly displays the "open" and "closed" status of access authority, which provides a quantitative reference for open access evaluation of scholarly journals. It can be said that this evaluation tool is an internationally recognized quantitative evaluation index for open access journals. However, it is not entirely suitable to use OAS to evaluate scholarly journals in China directly. Therefore, this study improves the relevant evaluation criteria by analyzing the actual situation in China.

In terms of reader rights, if the existing scholarly journals in China do not open the free reader rights of all articles to readers after a certain period of time, then these journals will not open the free reader rights of some articles at the same time. Therefore, few journals in China are in line with the standard of "Free and immediate readership rights to some, but not all, articles (including 'hybrid' models)". In view of this, this study modified the standard to "Not all articles (including some articles, 'hybrid' journals) can be read for free at the same time or after publication".

In terms of reuse rights, in order to ensure that readers have the right to use published articles to create new articles or research results, OAS evaluation tool sets "reuse rights" as an important evaluation index of open access journals, and further encourages the full reuse of research information or resources. However, Chinese journals generally pay little attention to the reuse of article content, and few of them issue official statements about reuse. In the absence of a special statement, Chinese scholarly journals are generally carried out in accordance with the Copyright Law of the People's Republic of China (here in after referred to as "Copyright Law"). To this end, this study is to adjust the evaluation standard of the "reuse rights" to "Issue license notices for reuse and recombination of article content ( 20 points)" "No special statements are issued regarding the reuse and recombination of the content (14 points)" "Publish restrictions on reuse and recombination of article content (7 points)" "Reuse and recombination of article content is prohibited ( 0 points)".

In terms of automatic posting, OAS evaluation tool lists PubMed Central, 
OpenAore and other free open access knowledge bases. It can be seen that the "trusted third-party knowledge repository" referred to here is an open access resource base with "free" as the core principle. In China, this kind of resource database mainly includes Chinese Highlights of Science paper Online (in the field of natural science), Chinese academic journals of Hans Publishers, National Center for Philosophy and Social Sciences Documentation, etc.

Based on the above analysis and explanation, this study finally constructed an openness evaluation framework for scholarly journals as shown in Table 2.

\section{Evaluation Results}

In the process of practical research, this study based on the construction of the evaluation framework of openness for scholarly journals in China, retrieved and analyzed manually the official website, Weibo and Wechat of the 284 samples of journals, and the six evaluation indexes of reader rights, reuse rights, copyrights, author posting rights, automatic posting, machine readability are evaluated and scored respectively. The total score is 100 points.

\subsection{Reader Rights}

Reader rights generally refer to readers' reading rights to articles published in journals, which is also the most basic index to measure the degree of open access of journals. Under the concept of open access, journal articles should be freely available to readers. Initiatives such as BOAI and Open Access 2020 suggest that fully Open Access journals should be able to be published at no cost to readers, highlighting the importance of free access. In terms of reader rights score, the largest number of journals in this sample got 0 points (66.55\%), followed by 5 points $(23.59 \%), 20$ points $(8.80 \%)$ and 16 points $(1.06 \%)$, and none of them got 12 points (see Table 3 for details). This means that more than half of the educational journals in China do not have open access and still require readers to pay to read articles, which goes against the current open access trend.

It is worth mentioning that at present, many journals are regularly opening some high-quality articles to readers through Wechat official accounts or official websites, which to some extent promotes the open access policy in China. Moreover, 25 sample journals immediately opened the reader rights of all articles through the official website at the same time of publication. Among them, two of the three journals with an impact factor greater than 3.0 have opened the reader rights. In general, although most journals in China still do not have open reader rights, many journals are gradually realizing the importance of open access to knowledge and information dissemination, which is first reflected in open reader rights in action.

\subsection{Reuse Rights}

By searching the sample journals, this study regrettably found that none of the 284 sample journals issued a special statement on the reuse and recombination of article content. In accordance with the Chinese publishing practice, if there is 
Table 2. The evaluation framework of openness for scholarly journals in China.

\begin{tabular}{|c|c|c|}
\hline The evaluation index & Score & Scoring criteria \\
\hline \multirow{5}{*}{ Reader rights } & 20 & $\begin{array}{l}\text { At the same time as the article is published, you will enjoy the right to read all } \\
\text { the content of the article for free }\end{array}$ \\
\hline & 16 & Enjoy free access to all articles within 6 months of publication \\
\hline & 12 & 6 months after the publication of all articles enjoy free reading rights \\
\hline & 5 & $\begin{array}{l}\text { Not all articles (including some articles, "hybrid" journals) can be read } \\
\text { for free at the same time or after publication }\end{array}$ \\
\hline & 0 & Subscription, membership, browsing or other fees are required to access all articles \\
\hline \multirow{4}{*}{ Reuse rights } & 20 & Issue license notices for reuse and recombination of article content \\
\hline & 14 & No special statements are issued regarding the reuse and recombination of the content \\
\hline & 7 & Publish restrictions on reuse and recombination of article content \\
\hline & 0 & Reuse and recombination of article content is prohibited \\
\hline \multirow{4}{*}{ Copyrights } & 16 & Authors own absolute copyright \\
\hline & 10 & $\begin{array}{l}\text { Authors reserve copyright/publisher's right to grant authors extensive reuse } \\
\text { rights (e.g., use published data in presentations/teaching, create derivatives) } \\
\text { and licensing rights (grant others to use them) }\end{array}$ \\
\hline & 4 & $\begin{array}{l}\text { Authors retain copyright/publishers grant authors partial reuse rights } \\
\text { (e.g., using published data in presentations/teaching, creating derivatives) }\end{array}$ \\
\hline & 0 & Publishers own the copyright and allows only fair use by the author \\
\hline \multirow{5}{*}{ Author posting rights } & 16 & $\begin{array}{l}\text { Authors may post any version of the article on any website or Wechat or } \\
\text { Weibo platform after the article is published }\end{array}$ \\
\hline & 10 & $\begin{array}{l}\text { Authors may publish certain versions of the content determined by publishers on any } \\
\text { website or Wechat or Weibo platform at the same time as the article is published }\end{array}$ \\
\hline & 6 & $\begin{array}{l}\text { Authors may publish certain versions of the content as determined by publishers on } \\
\text { any website or Wechat or Weibo platform within a certain period of time (the specific } \\
\text { delay period is determined by the publisher) after the publication of the article }\end{array}$ \\
\hline & 4 & $\begin{array}{l}\text { At the same time or after the publication of the article, the authors may publish } \\
\text { certain versions of the content determined by publishers on specific } \\
\text { websites or Wechat and Weibo platforms }\end{array}$ \\
\hline & 0 & $\begin{array}{l}\text { Authors shall not publish any version of the content to any website or } \\
\text { Wechat or Weibo platform at any time }\end{array}$ \\
\hline \multirow{4}{*}{ Automatic posting } & 12 & $\begin{array}{l}\text { At the same time of publication, the journal automatically publishes the backup of all } \\
\text { articles to a trusted third party knowledge repository (e.g. national Journal database of } \\
\text { Philosophy and Social Sciences). }\end{array}$ \\
\hline & 8 & $\begin{array}{l}\text { The journal automatically releases copies of all articles to a trusted third } \\
\text { party repository of knowledge within } 6 \text { months of publication (e.g., Database } \\
\text { of National Scholarly journals of Philosophy and Social Sciences) }\end{array}$ \\
\hline & 4 & $\begin{array}{l}\text { The journal automatically publishes copies of all articles to a trusted third party } \\
\text { repository of knowledge within } 12 \text { months of publication (e.g., National } \\
\text { Database of Scholarly journals in Philosophy and social Sciences) }\end{array}$ \\
\hline & 0 & $\begin{array}{l}\text { The journal automatically publishes a backup of some (but not all) articles to a } \\
\text { trusted third party knowledge repository (e.g., Database of National Scholarly } \\
\text { journals of Philosophy and Social Sciences) within } 12 \text { months of publication. }\end{array}$ \\
\hline
\end{tabular}




\begin{tabular}{|c|c|c|}
\hline \multirow{5}{*}{ Machine readability } & 16 & $\begin{array}{l}\text { The full text of the article, metadata, supporting data (including formatting and } \\
\text { semantic markup), and citations are available through an application } \\
\text { programming interface (API) and publicly published notes }\end{array}$ \\
\hline & 12 & $\begin{array}{l}\text { The full text of the article, metadata, and citations are available through an } \\
\text { application programming interface (API) and publicly published notes }\end{array}$ \\
\hline & 8 & $\begin{array}{l}\text { Publish instructions publicly, allowing full text, metadata, and citations of } \\
\text { articles to be crawled without permission }\end{array}$ \\
\hline & 4 & $\begin{array}{l}\text { Publish instructions publicly, allowing full text, metadata, and citations of } \\
\text { articles to be crawled with permission }\end{array}$ \\
\hline & 0 & The full text of the article cannot be crawled \\
\hline
\end{tabular}

Table 3. Reader rights scores of sample journals.

\begin{tabular}{ccc}
\hline Scores & Number of journals & Percentage of journals \\
\hline 20 & 25 & $8.80 \%$ \\
16 & 3 & $1.06 \%$ \\
12 & 0 & $0 \%$ \\
5 & 67 & $23.59 \%$ \\
0 & 189 & $66.55 \%$ \\
\hline
\end{tabular}

no clear statement, it is generally carried out according to the relevant provisions of the Copyright Law.

According to the law, the copyright of a work created by adaptation, translation, annotation or arrangement of a pre-existing work shall be enjoyed by the adaptor, translator, annotation or arranger, but the exercise of copyright shall not infringe on the copyright of the original work. Therefore, from the perspective of "Copyright Law", Chinese scholarly journals are more tolerant of the license of article content reuse. Given that none of the sample journals made a specific statement about the reuse rights, they all scored 14 points.

\subsection{Copyrights}

Copyrights refer to the personal and property rights legally enjoyed by the creators of literary, artistic and scientific works over their created works. According to the Copyright Law of the People's Republic of China, copyrights include personal rights and property rights, among which personal rights refer to "the personal rights that the author enjoys according to law due to the creation of works". Such rights are permanent and inalienable and cannot be transferred or divisible. Therefore, the copyrights index here mainly refers to the property rights in copyright, including the right of reproduction, the right of distribution, the right of information network transmission, the right of modification, the right of translation and the right of compilation.

Of the 284 sample journals, a total of 124 have issued copyright agreements, of 
which 102 journals specify that the author authorizes that "the publisher owns the copyright and the author only uses it reasonably". For example, in the copyright agreement, it is stated that "We have the right to modify the words of our submissions... The author of the paper voluntarily transfers to the editorial Department the compilation rights (part or all of the paper), translation rights, printing and electronic copy rights, network transmission rights and distribution rights. The author of the paper shall not license the use of the paper in any form, but the author of the paper may quote (or translate) some of the content of the paper in subsequent works or compile it in the author's non-journal collection." But at the same time, 68 sample journals allow authors to partially reuse their articles, mainly allowing them to continue to use the articles under the following circumstances: patent application, academic reports and lectures, non-commercial academic exchanges, other activities permitted and authorized by the editorial department. Although the 68 sample journals clearly transfer the copyright to the publisher, they also authorize the authors to partially reuse the copyright. In order to highlight the difference, this study considers that 68 sample journals should get 4 points in the copyrights index, while the remaining 38 journals get 0 point in the copyrights index.

In 22 other sample journals, although the copyright agreement is issued, the authors only transferred part of the copyright. For example, there is a description in the publishing agreement that "the copyright belongs to the journal and the author jointly" and "for papers accepted by the journal, please authorize the journal to publish on paper, CD-ROM and network". Although publishers allow authors partial reuse rights, authors no longer have the right to license, that is, to grant others the right to republish. Therefore, these 22 sample journals meet the evaluation criteria of "authors retain copyright/publishers allow authors to partially reuse rights" and receive 4 points.

For journals that do not publish copyright agreements, this study considers that the authors have absolute copyright, which means that the score is 16 points. Although some journal publishers hold that the property right in copyright should be transferred to the publishers by default if there is no copyright agreement issued, this does not conform to the legal norms in a strict sense. From the legal level, when the authors and the publishers have copyright disputes, there is no copyright agreement is controversial, in other words, the author did not authorize the transfer of copyright. Therefore, 156 journals without publishing copyright agreements were rated as meeting the evaluation criterion of "The authors own absolute copyright", with a score of 16 points. The final score of copyrights indicators is shown in Table 4.

\subsection{Author Posting Rights}

In terms of author posting rights, OAS evaluation tool equates website and knowledge warehouse, but the usage of the two will be different in China. Generally speaking, knowledge warehouse refers to knowledge storage databases 
Table 4. Copyrights scores of sample journals.

\begin{tabular}{ccc}
\hline Scores & Number of journals & Percentage of journals \\
\hline 16 & 156 & $54.93 \%$ \\
14 & 0 & $0 \%$ \\
4 & 90 & $31.69 \%$ \\
0 & 38 & $13.38 \%$ \\
\hline
\end{tabular}

such as CNKI, Wanfang and CQVIP. Knowledge resources in the database can only be published by publishers, and authors do not have the right to publish online. However, the author can publish the knowledge resources online on the website or through Wechat and Weibo. Through analysis, this study found that although no sample journal online release for a detailed description of its authors, but in the copyright agreement or submission guidelines, involves the "authors cannot publish the paper in any form elsewhere", etc, meet the evaluation criteria "authors shall not publish any version of the content to any website or Wechat or Weibo platform at any time". Therefore, the scores of the 284 sample journals in the author posting rights are 0 .

\subsection{Automatic Posting}

By searching the open access knowledge repository of Chinese Highlights of Sciencepaper Online, Chinese academic journals of Hans Publishers, National Center for Philosophy and Social Sciences Documentation, the paper counted out 114 sample journals having automatically released a backup of all articles to a trusted third party knowledge repository within 12 months after publication. The rest of the journals are not open access to trusted third party repositories of knowledge, with a score of 0 points. The scores of sample journals in automatic posting are shown in Table 5.

\subsection{Machine Readability}

In machine readability terms, API (Application Programming Interface) refers to predefined interfaces (such as functions, HTTP interfaces) or conventions for connecting different parts of a software system. An open API allows users to access platform information without having to access the source code. However, we found that Chinese scholarly journals (especially education and other humanities and social sciences journals) generally did not understand the concept of machine readability or API, so almost no journals issued public explanation of "machine readability". Meanwhile, there is also no indication that full text, metadata, supporting data, and citations can be retrieved from the API. Therefore, the score of the 284 sample journals in the machine readability is 0 points. 
Table 5. Automatic posting scores of sample journals.

\begin{tabular}{ccc}
\hline Scores & Number of journals & Percentage of journals \\
\hline 16 & 0 & $0 \%$ \\
10 & 0 & $0 \%$ \\
4 & 114 & $40.14 \%$ \\
0 & 170 & $59.86 \%$ \\
\hline
\end{tabular}

Table 6. Total open access scores of sample journals.

\begin{tabular}{ccc}
\hline Scores & Number of journals & Percentage of journals \\
\hline $50-55$ & 10 & $3.52 \%$ \\
$40-49$ & 11 & $3.87 \%$ \\
$30-39$ & 155 & $54.58 \%$ \\
$20-29$ & 39 & $13.73 \%$ \\
$10-19$ & 69 & $24.30 \%$ \\
\hline
\end{tabular}

\subsection{Overall Scores}

Based on the scores of the six indicators, the overall evaluation of sample journals' open access is shown in Table 6. Compared with foreign open access journals, the level of open access of scholarly journals in China is low, with the highest score range of 50 - 55 points only has 10 journals, accounting for $3.52 \%$ of the total number of sample journals. In the sample journals, the largest number of journals has a score range of 30 - 39 points, well below the level of international open access journals. Therefore, the level of open access of scholarly journals in China is not high, and the open access policy needs to be further promoted.

\section{Conclusion}

Through the evaluation of educational journals in China, it is found that the openness of academic periodicals in China is still low. From the perspective of reader rights, reuse rights, copyrights, author posting rights, automatic posting, machine readability, Chinese publishers are not paying enough attention and importance to open access. It is worth mentioning that the development of OA journals is not only the "matter" of the publishers, but also the indispensable promoters, including the government, libraries, universities, scientific research institutions and authors, some of which can even play a leading role. In recent years, a considerable number of scholarly journals have joined the ranks of open access in China, and the number continues to grow. However, there are still some publishers and researchers who are skeptical about the value and significance of open access, and even many researchers, authors and readers do not know about open access journals. This is also an important reason why the existing public open access platforms and open access journals in China are not in- 
fluential enough. Therefore, universities, libraries and research institutions should increase the publicity of the concept of "open access", especially the publicity of OA journals and public open access platforms, and improve the popularity and attention of OA journals and the concept of "open access" among researchers, authors and readers.

\section{Funding}

2020 annual project of Zhejiang Province Association of Higher Education "Research on the degrees and modes of open access of Chinese scholarly journals in the era of big data" (KT2020100).

\section{Conflicts of Interest}

The author declares no conflicts of interest.

\section{References}

[1] Suber, P. (2012) Open Access. MIT Press, Cambridge, MA. https://doi.org/10.7551/mitpress/9286.001.0001

[2] Teplitzky, S. and Phillips, M.E. (2016) Evaluating the Impact of Open Access at Berkeley: Results from the 2015 Survey of Berkeley Research Impact Initiative (BRII) Funding Recipients. College \& Research Libraries, 77, 568-581. https://doi.org/10.5860/crl.77.5.568

[3] Nariani, R. and Fernandez, L. (2012) Open Access Publishing: What Authors Want. College \& Research Libraries, 73, 182-195. https://doi.org/10.5860/crl-203

[4] Beard, R.M. (2016) An Investigation of Graduate Student Knowledge and Usage of Open-Access Journals. Journal of Electronic Resources Librarianship, 28, 25-32. https://doi.org/10.1080/1941126X.2016.1130453

[5] Neuman, Y. and Laakso, M. (2017) Balancing Ideology and Feasibility: A Case Study on Adopting and Evaluating Open Access Publishing Models for a Society Journal within Philosophy. Information Research, 22, No. 4.

[6] Zawacki-Richter, O., Anderson, T. and Tuncay, N. (2010) The Growing Impact of Open Access Distance Education Journals: A Bibliometric Analysis. Journal of Distance Education, 24, No. 3.

[7] McCabe, M.J., Snyder, C.M. and Fagin, A. (2013) Open Access versus Traditional Journal Pricing: Using a Simple "Platform Market" Model to Understand Which Will Win (and Which Should). The Journal of Academic Librarianship, 39, 11-19. https://doi.org/10.1016/j.acalib.2012.11.035

[8] Arendt, J., Peacemaker, B., et al. (2019) Same Question, Different World: Replicating an Open Access Research Impact Study. College \& Research Libraries, 80, 303 318. https://doi.org/10.5860/crl.80.3.303 